\title{
An Intelligent Detection System Development for Local Faults in a Ball Bearing
}

\author{
Jing Liu \\ State Key Laboratory of Mechanical Transmission, Chongqing University, Chongqing, 400030, China. \\ College Engineering, Chongqing University, Chongqing, 400030, China. \\ Linfeng Wang and Li Zhou \\ College Engineering, Chongqing University, Chongqing, 400030, China.
}

\author{
Liming Wang and Zhifeng Shi \\ State Key Laboratory of Mechanical Transmission, Chongqing University, Chongqing, 400030, China. \\ College Engineering, Chongqing University, Chongqing, 400030, China.
}

\begin{abstract}
(Received 24 January 2019; accepted 21 March 2019)
Local faults can be produced in ball bearings during their manufacturing process. An efficient, fast and accurate local fault detection method can help improve the quality of ball bearings. To overcome this problem, an intelligent detection system for a ball bearing with the local faults is developed based on the NI LabVIEW software. This system includes the determination of bearing fault parameters, signal acquisition, envelope analysis, time-domain parameter analysis and bearing fault status modules. In this system, the frequency-domain feature method is based on the envelope demodulation analysis, the effective statistical indexes, and the Pearson correlation coefficient. The frequency-domain feature method is used to determine the threshold range for each fault level in the system. This system can in turn be used to determine the fault location and sizes for the ball bearings. A case study for the calculation and analysis for the frequency and time-domain acceleration is presented to predict the location and size of the local faults in a ball bearing. The test data from the Case Western Reserve University Bearing Data Center is used to verify the developed intelligent detection system for local faults in the ball bearing. The results show that the proposed detection system can be used to detect the local fault in the ball bearings.
\end{abstract}

\section{INTRODUCTION}

Ball bearings are the key components of rotating machinery systems. Ball bearings can ensure the stable operation conditions of the system. However, different faults, including local and distribution faults, may be produced during the manufacturing process. ${ }^{1}$ Thus, an accurate and efficient detection method is very useful for detecting the faults in the ball bearings. This work is given to present an intelligent detection system for detecting the local faults in the ball bearings.

Many works were reported to study different detection methods for the local faults in rolling element bearings. Song et al., Cui et al., Guo et al., Liu et al., Wang et al., Dong et al., and Moosavian et al. proposed the frequency-domain and time-domain features to determine the operational status of the bearing systems. ${ }^{2-8}$ Song et al., Wang et al., and Cui et al. proposed some useful methods for diagnosing and analyzing the local faults in the bearing systems. ${ }^{9-13}$ Zhao et al. proposed some new methods for predicting the location and sizes of the weak faults in the bearing systems. ${ }^{14,15}$ Liu et al. proposed some new dynamic modelling methods for the vibration analysis of bearing systems with localized faults. ${ }^{16-18}$ Mishta et al. used the envelope analysis and threshold wavelet denoising methods to detect the faults of rolling bearings. ${ }^{19,20}$ This method can extract fault-related symptoms for the low speed conditions. Ali et al. presented the artifcial Neural
Network bearing defects system based on the health index to classify the bearing defects. ${ }^{21}$ Hoang et al. developed the automatic bearing fault detect system combining with convolutional Neural Network and vibration image. ${ }^{22}$ This method did not require any feature extraction techniques. Fan, Xie, and $\mathrm{He}$ used LabVIEW, MATLAB and VC++ to develop the detection systems for the local faults in the ball bearings. The systems developed by Fan, Xie, and He are based on frequency and time-domain vibration features. ${ }^{23-25}$ This detection systems includes data collection, signal analysis, signal transmission, and fault detection modules. Although the above system can detect fault generation, they cannot detect the fault size range. In practice, both the generation and size range should be detected in order to classify the different faults that are generated in the bearing system. The purpose of this work is to introduce a system that can detect both the generation and size rang of the local faults.

In this paper, an intelligent detection system for a ball bearing with local faults is developed based on the NI LabVIEW software. NI LabVIEW software includes bearing fault parameter determination, signal acquisition, envelope analysis, time-domain parameter analysis and bearing fault status modules. The frequency-domain feature method is based on the envelope demodulation analysis, the effective statistical indexes, and the Pearson correlation coefficient. The frequency-domain feature is used to determine the threshold range for each fault 


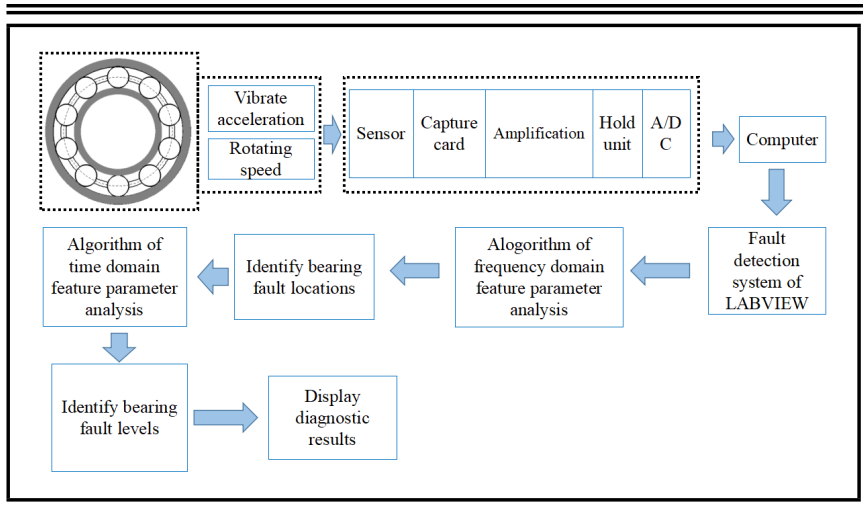

Figure 1. A functional framework of the defect detection system software for ball bearings.

level in the system. This system can be used to determine the fault location and sizes. The input bearing geometrics can be memorized in the system. A case study for the calculation and analysis for the frequency- and time-domain accelerations is presented to predict the location and size of the local fault in the ball bearing. The test data from the Case Western Reserve University Bearing Data Center is used to verify the developed intelligent detection system for local faults in a rolling bearing.

\section{AN INTELLIGENT DETECTION SYSTEM FOR LOCAL FAULTS IN THE BALL BEARINGS}

The developed intelligent detection system for the local faults in ball bearings included fault parameter determination, signal acquisition, envelope analysis, time-domain parameter analysis and bearing fault status. The functional framework of the detection system is given in Fig. 1 .

In the envelope analysis module, the characteristic frequencies of the stable vibration signal of the tested bearing were used to compare with those from the theoretical method. ${ }^{26}$ The compared results were used to determine the inner race fault, outer race fault, and ball fault. In the time-domain parameter analysis module, the time-domain parameters, such as maximum value, peak-to-peak value, mean value, kurtosis, and RMS value, were used to determine the fault size range based on the defined threshold value in the detection system. More details for the parameters used for different bearing fault cases are listed in Table 1. If $60 \%$ of the listed parameters were located in the defined threshold range, the fault size range was determined. The main interface of the defect detection system software for ball bearings is shown in Fig. 2 .

\subsection{Geometrics and Operational Parameters of the Ball Bearing}

The detection system was used to detect the faults in different bearing types. Thus, the geometrics and operational parameters of the tested bearing types was entered into the detection system. The rotational speed of the bearing was entered into the detection system as well. When the geometrics and operational parameters of a new bearing type was entered into the detection system, all of the parameters that had been entered were stored in the system. The block diagram and front panel

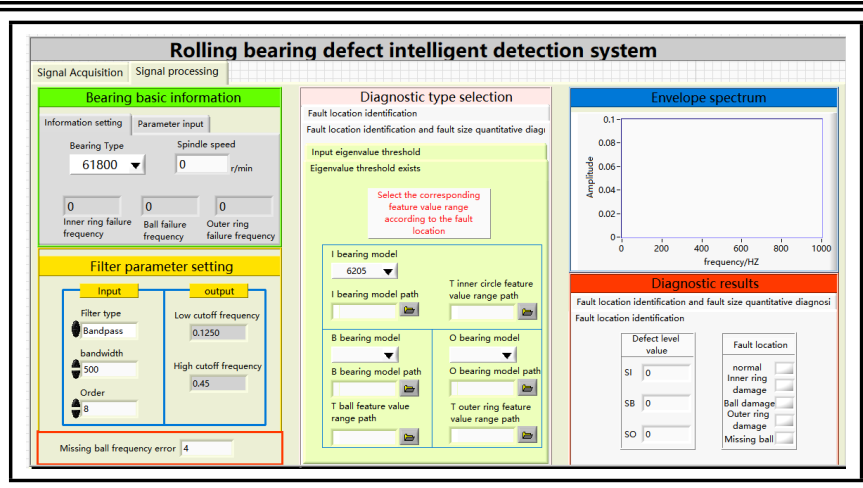

Figure 2. The main interface of the defect detection system software for ball bearings.

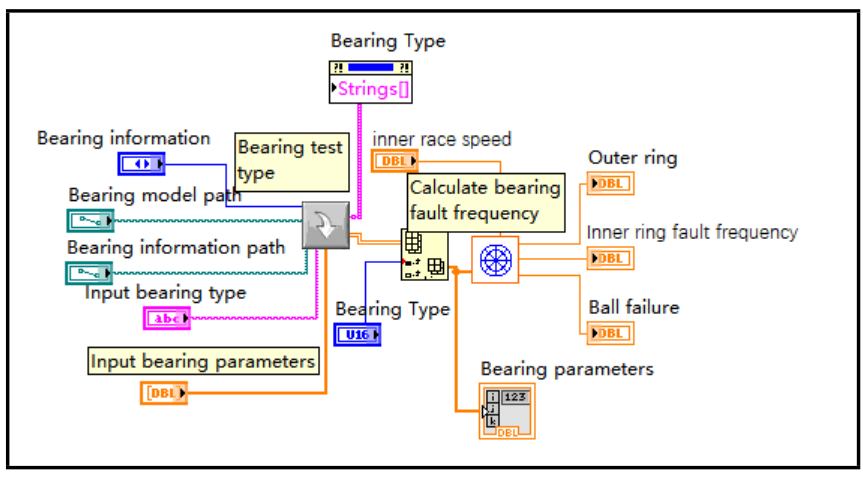

Figure 3. A block diagram for setting bearing information.

for setting bearing information are shown in Figs. 3 and 4, respectively.

\subsection{Signal Acquisition Module}

In the signal acquisition module, the acceleration signal from the tested bearing was collected. An accelerometer located on the outer race of the tested bearing was used to obtain the acceleration signal. The acceleration signal was orderly processed by the amplification, anti-aliasing filtering, sampling retention, and A/D conversion. Then, the processed signal was entered into the detection system. The sampling clock was $1 \mathrm{~s}$ in this system. The collected acceleration signal was then used in the following modules. The front panel of the signal acquisition module is shown in Fig. 5.

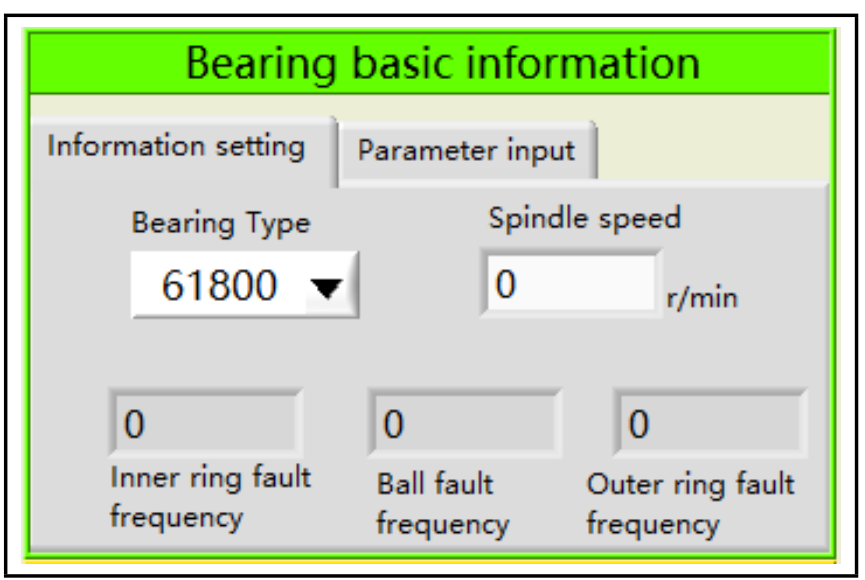

Figure 4. A front panel for setting bearing information. 


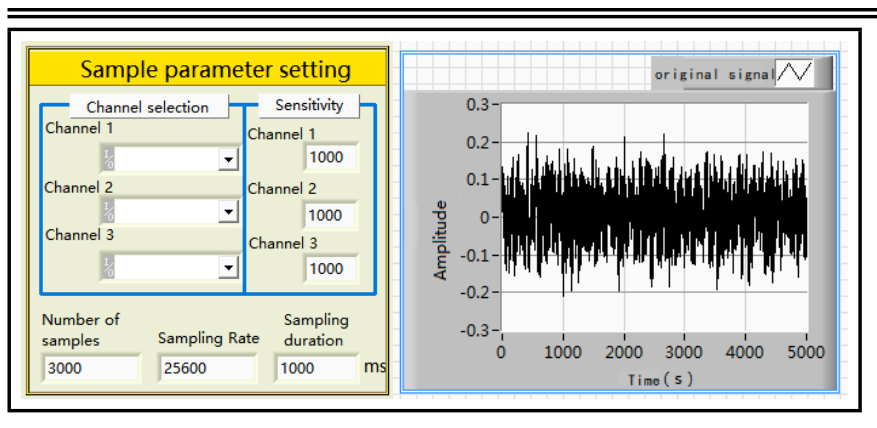

Figure 5. Front panel of signal acquisition module.

\subsection{Envelope Analysis Module}

The envelope analysis method was the main technique used in the detection of faults in ball bearings. For a vibration signal $x(t)$, the equation processed by the Hilbert transfer method was used. ${ }^{26}$

$$
H[x(t)]=\frac{1}{\pi} \int \frac{x(t-\tau)}{\tau} d \tau=x(t) \cdot \frac{1}{\pi \tau} .
$$

Then, the envelope signal of $\mathrm{x}(\mathrm{t})$ was determined by

$$
A(t)=\sqrt{x^{2}(t)+H^{2}[x(t)]} .
$$

The bearing characteristic frequencies were obtained from the envelope signal in Eq. (2). The characteristic frequencies included the ball passing frequencies BPFO (for the outer race), BPFI (for the inner race), and BSF (for the balls). More details for the calculation method for the ball passing frequencies are given by Smith, et al. ${ }^{26}$ The BFPO was determined by

$$
\mathrm{BFPO}=\frac{n f_{r}}{2}\left(1-\frac{D_{W}}{D_{b}} \cos \phi\right),
$$

where $f_{r}$ was the speed of shaft, $n$ was the number of balls, $\phi$ was the contact angle, $D_{w}$ was the ball diameter, and $D_{b}$ was the pitch diameter. The BPFI was determined by

$$
\mathrm{BFPI}=\frac{n f_{r}}{2}\left(1+\frac{D_{W}}{D_{b}} \cos \phi\right) .
$$

The BSF was determined by

$$
\mathrm{BSF}=\frac{D_{b} f_{r}}{D_{W}}\left[1-\left(\frac{D_{W}}{D_{b}} \cos \phi\right)^{2}\right] .
$$

Since the skidding in the bearing and unstable input speed appeared during the testing process, the characteristic frequencies differed from the theoretical method. ${ }^{26}$ To overcome this problem, the permissible frequency error $\left(f_{w}\right)$ around the fault frequency $\left(f_{d}\right)$ was defined. This means that the maximum amplitude of the peak frequencies in the permissible frequency error range were defined as the amplitude of the fault frequency. It was defined as

$$
\begin{gathered}
A_{d i}(f)=\max (A(f)), \\
i f_{d}-0.5 f_{w} \leq f \leq i f_{d}+0.5 f_{w},
\end{gathered}
$$

where $A_{d}(f)$ was the amplitudes of the fault frequency and the harmonics in the envelope spectrum; $A(f)$ was the amplitude of the envelope spectrum; and $i$ was $1,2,3, \ldots$ Moreover, the

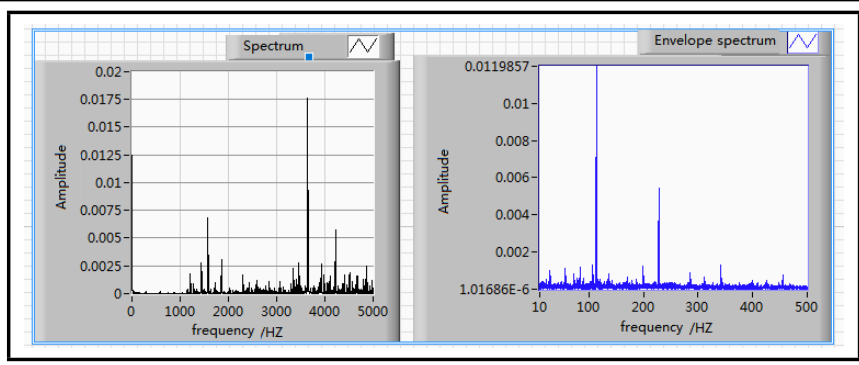

Figure 6. A front panel of frequency domain fault analysis module.

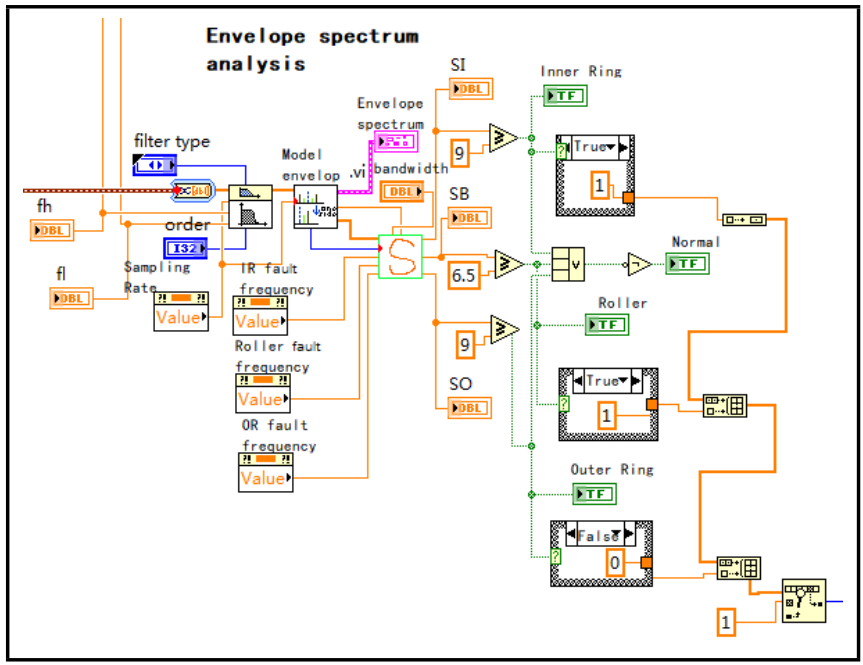

Figure 7. A front panel of frequency domain fault analysis module.

amplitude of the peak frequency in the envelope spectrum was affected by the noise in the vibration signal, which may produce some misjudgment. ${ }^{27,28}$ To obtain a more accurate result, a parameter was used to improve the signal noise ratio, which was determined by

$$
s=\frac{\frac{1}{M} \sum_{i=1}^{M} A_{d i}(f)}{\sqrt{\frac{1}{N} \sum_{j=1}^{N} A_{j}^{2}(f)}},
$$

where $M$ was the maximum factor of the fault frequency. Since the amplitude at the multiplier was attenuated faster, $M$ generally took $2 \sim 4$; and $N$ was the sample number. ${ }^{25}$

Based on the analysis results of the vibration signal of the healthy and defective bearings, the threshold of the inner race fault, outer race fault, and ball fault were determined. When the parameter $s$ was larger than the relative threshold, the corresponding fault case was determined. The front panel of the frequency domain feature analysis module and the block diagram of frequency-domain feature analysis are shown in Figs. 6 and 7, respectively.

\subsection{Time-Domain Parameter Analysis Module}

The characteristics of the vibration signals for different fault sizes cases were different, which was used to determine the fault size range. ${ }^{29,30}$ The Pearson correlation coefficient (PCC) was used to determine the effective time-domain statistical in- 
(a)

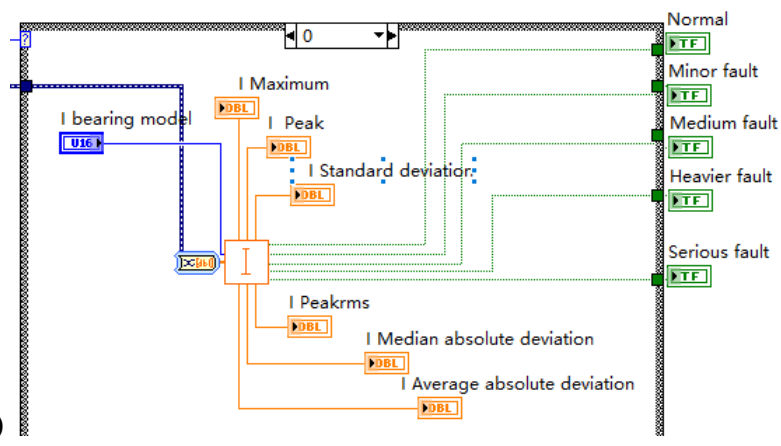

(b)
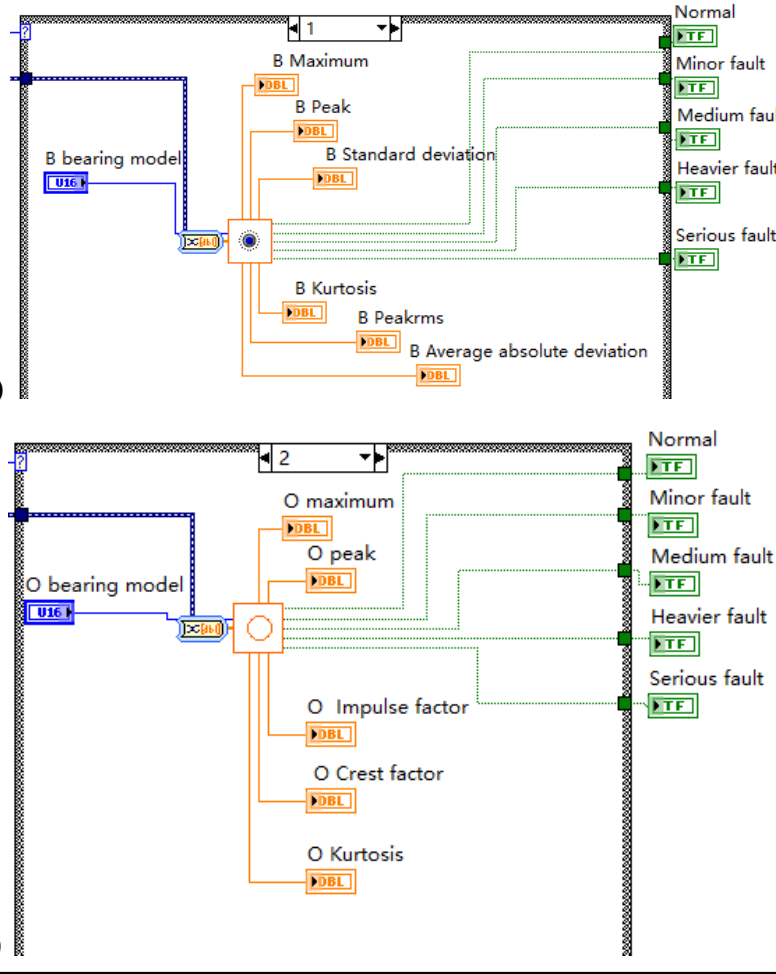

Figure 8. A block diagram of time-domain analysis module. (a) Inner race fault detection system, (b) ball fault detection system, and (c) outer race fault detection system.

dexes. It was defined by Liu, et al. as ${ }^{29,30}$

$$
\rho=\frac{\sum_{i=1}^{N_{h}}\left(x_{i}-\bar{x}\right)\left(y_{i}-\bar{y}\right)}{\sqrt{\sum_{i=1}^{N_{h}}\left(x_{i}-\bar{x}\right)^{2}} \sqrt{\sum_{i=1}^{N_{h}}\left(y_{i}-\bar{y}\right)^{2}}},
$$

where $x_{i}$ and $y_{i}$ were the feature and label values. The values $\bar{x}$ and $\bar{y}$ were the mean values for $x$ and $y$. In this case, $x=\left[x 1, x 2, \ldots, x_{N_{h}}\right]^{T}$ and $y=$ $[0,0.0248,0.0497,0.0745,0.0993]^{T}$. The value $y$ represented the healthy, slight, moderate, severe, and very severe faults, whose values were obtained by using the PCC. ${ }^{30}$ This method was based on the testing data from the Case Western Reserve University data. ${ }^{31}$ As discussed by Liu, et al., 5 or 6 statistical indexes were used to determine the fault size range. ${ }^{30}$ According to the different fault size ranges including healthy, slight, moderate, severe, and very severe cases, different threshold values were used. In this detection system, different statistical indexes were used for different fault cases. The effective statistical indexes used in the detection system are listed in Table 1.

According to the fault location, different effective statistical indexes were used to determine the fault size range. The
Table 1. Effective statistical indexes for different defect location cases

\begin{tabular}{|c|c|}
\hline Fault location & Effective statistical indexes \\
\hline Inner race & $\begin{array}{l}\text { Maximum value, peak-to-peak value } \\
\text { (PTP), median absolute deviation, } \\
\text { standard deviation, mean absolute } \\
\text { deviation, RMS, Peak/RMS; }\end{array}$ \\
\hline Ball & $\begin{array}{c}\text { Maximum value, PTP value, } \\
\text { standard deviation, median absolute } \\
\text { deviation, mean absolute deviation, } \\
\text { RMS, Peak/RMS; }\end{array}$ \\
\hline Outer race & $\begin{array}{l}\text { Maximum value, PTP value, } \\
\text { impulse factor, crest factor, kurtosis. }\end{array}$ \\
\hline
\end{tabular}

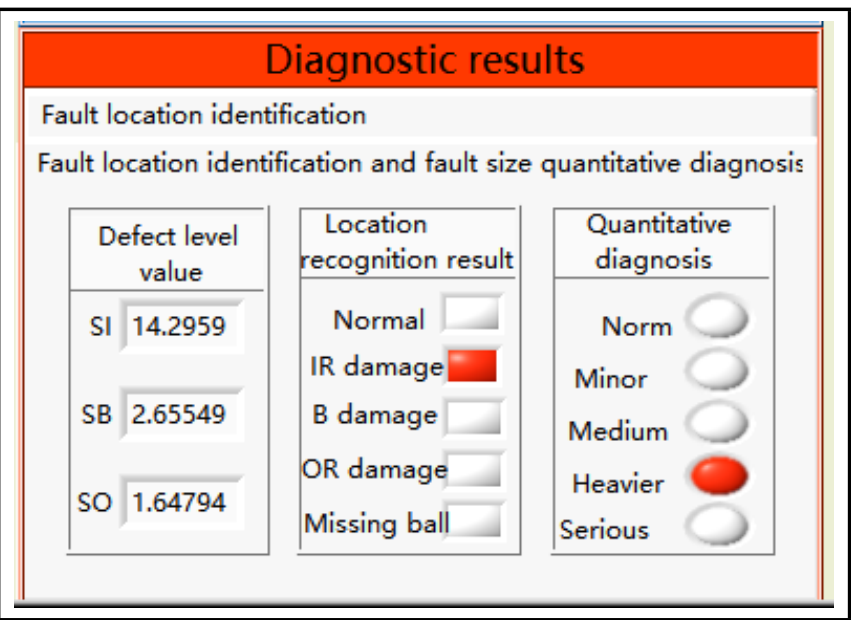

Figure 9. Diagnostic results.

block diagram of time-domain analysis module for the inner race fault detection system, ball fault detection system, and outer race detection system are shown in Fig. 8. The interface for the diagnostic results are shown in Fig. 9. In the detection system, the thresholds of the effective statistics used in the detection system changed with each bearing type. This means that the thresholds of the effective statistics for each bearing type were calculated in the detection system. Moreover, the system was used to detect the fault location and sizes for roller bearings since the relative methods for the ball bearings and roller bearings were similar.

\section{RESULTS ANALYSIS}

\subsection{Fault Location Detection}

To validate the detection system, the testing data in Loparo under different operational conditions are used here. ${ }^{31}$ The sample frequency is $12 \mathrm{~K}$. The load and speed are $735 \mathrm{~W} / 1772 \mathrm{r} / \mathrm{min}$ and $1470 \mathrm{~W} / 1772 \mathrm{r} / \mathrm{min}$, respectively. For the case of $735 \mathrm{~W} / 1772 \mathrm{r} / \mathrm{min}$, the healthy, inner race fault and outer race fault cases are used. For the case of $1470 \mathrm{~W} / 1772 \mathrm{r} / \mathrm{min}$, the ball fault case is used. The studied accelerations and their envelope spectra are shown in Fig. 10. In Fig. 10, $\beta$ represents the ratio of the fault size to the track width in order to indicate the degree of fault. Note, the relative bearing fault frequencies (BPFO for outer race fault, BPFI for inner race fault, and BSF for ball fault) for the three fault cases are clearly observed in the envelope spectra. When the fault location is determined, the threshold of the parameter $s$ 


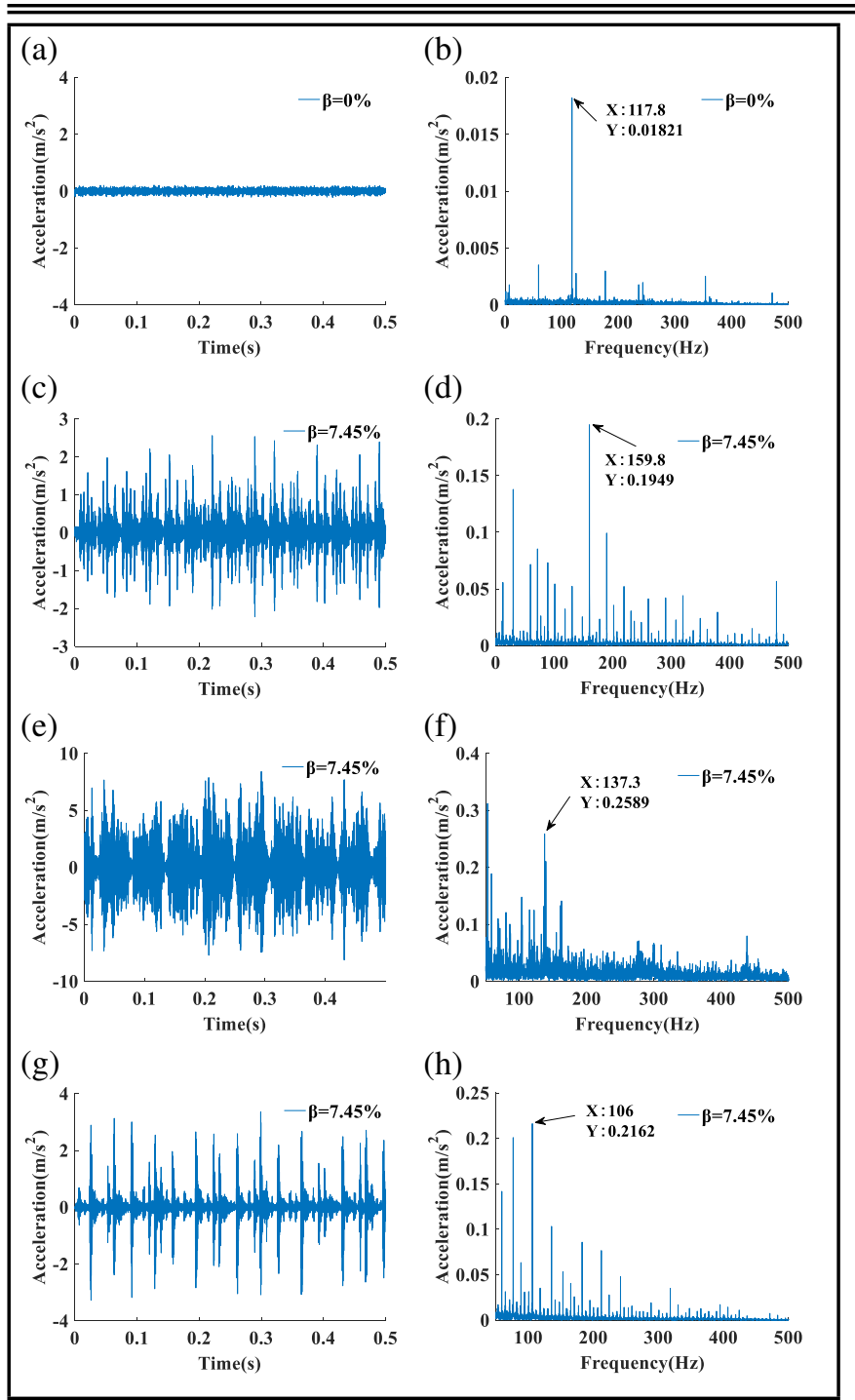

Figure 10. Time and frequency-domain vibration signals used for different cases of defect location.

is used to determine the fault size range. Here, based on the testing date in Loparo, the thresholds of $s$ for the inner race fault, ball fault, and outer race fault are defined as $12,6.5$, and 12 , respectively. ${ }^{31}$

For Fig. 10, (a) shows the acceleration of the healthy bearing, (b) shows the envelope spectrum for the healthy bearing, (c) show the acceleration of the inner race fault, (d) shows the envelope spectrum for the inner race fault, (e) shows the acceleration of the ball fault, (f) shows the envelope spectrum for the ball fault, (g) shows the acceleration of the outer race fault, and (h) shows envelope spectrum for the outer race fault.

As shown in Fig. 10, the RMS value of the ball fault case is slightly larger than that of the healthy case. The reason for the fault case having a slightly larger value is that the ball fault region may be not located in the contact zone due to its spinning. Thus, it is difficult to determine the ball fault when only the RMS value is used. The RMS value of the inner and outer race fault cases are larger than that of the healthy case. Thus, the amplitude of peak frequencies and the relative harmonics in their envelope spectra are larger than those of the healthy case. Moreover, there are some clear peak frequencies in the envelope spectrum of the healthy case. If the amplitudes of the peak frequencies in the envelope spectrum are only used to de-

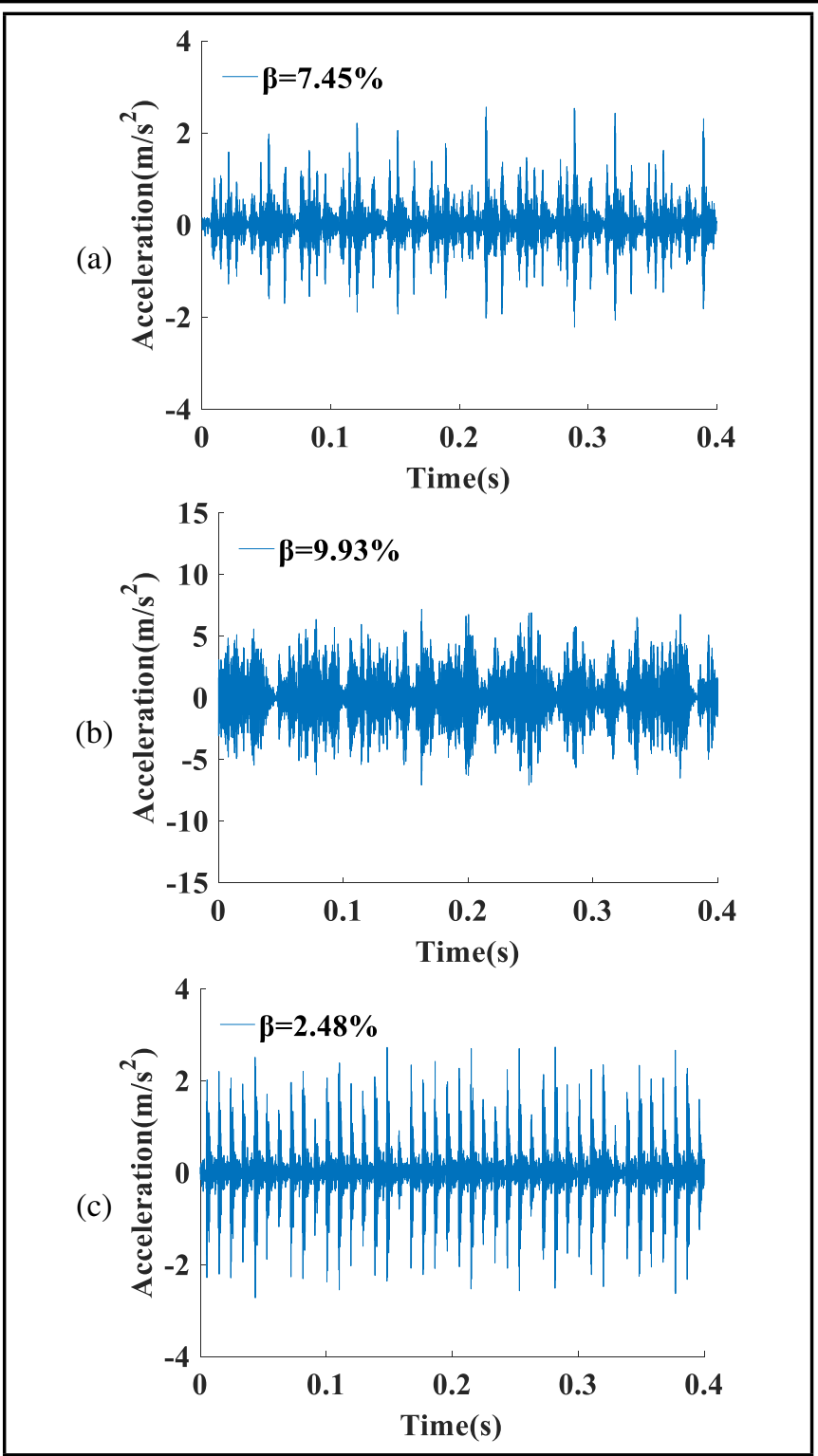

Figure 11. Vibration signals for three bearing defect cases. (a) Inner race fault, (b) ball fault, and (c) outer race fault.

termine the fault case, some misjudgments may be produced.

The detection results of the cases in Fig. 10 are shown in Table 2. Note that the value of $s$ for the healthy case is smaller than the above defined threshold. The variable $s$ can be defined as the healthy bearing. The values of $s$ for the inner and outer race fault cases are larger than the above defined threshold. They can be defined as the bearings with inner and outer race faults, respectively. For the ball fault case, the value of $s$ is larger than the above defined threshold and that of the healthy case. However, they are smaller than those of the inner and outer race fault cases. Thus, it can be defined as a bearing with a ball fault, a slight inner or outer race fault case.

Moreover, 17 cases from ${ }^{31}$ are used to show the detection results, as shown in Table 3. Here, four bearing fault types with different loads, including healthy bearing (cases 1 to 4 ), inner race fault (cases 5 to 8), ball fault (cases 9 to 12), and outer race fault (cases 13 to 17) have been listed. Normal is the healthy bearing, I-Defect is the bearing with the inner race fault, B-Defect is the bearing with the ball fault, and O-Defect is the outer race fault. Note that all cases can be detected by 
Table 2. Recognition results of bearing defect positions

\begin{tabular}{|c|c|c|c|c|c|c|}
\hline \multirow[b]{2}{*}{$\begin{array}{c}\text { Fault } \\
\text { location }\end{array}$} & \multicolumn{2}{|c|}{ Fault frequency $(\mathrm{Hz})$} & \multirow[b]{2}{*}{$\begin{array}{l}\text { RMS } \\
/ \mathrm{dB}\end{array}$} & \multicolumn{3}{|c|}{ Fault size range parameter } \\
\hline & $\begin{array}{c}\text { Theoretical } \\
\text { results }\end{array}$ & $\begin{array}{c}\text { Test } \\
\text { results }\end{array}$ & & $\begin{array}{c}\text { Inner race } \\
s_{i}\end{array}$ & $\begin{array}{c}\text { Ball } \\
s_{b}\end{array}$ & $\begin{array}{c}\text { Outer race } \\
s_{O}\end{array}$ \\
\hline Healthy & - & - & 0.0664 & 2.66 & 1.71 & 3.16 \\
\hline Inner race & 159.9 & 159.8 & 0.4418 & 19.93 & 3.32 & 2.57 \\
\hline Ball & 137.5 & 138.2 & 0.1291 & 8.47 & 9.05 & 10.76 \\
\hline Outer race & 105.8 & 106.0 & 0.5614 & 0.77 & 0.75 & 13.74 \\
\hline
\end{tabular}

Table 3. Detection results of the defect positions of bearing 6025 .

\begin{tabular}{ccccccc}
\hline Case & Fault status & SI & SB & SO & $\begin{array}{c}\text { Detection } \\
\text { results }\end{array}$ & W/r/min \\
\hline 1 & Healthy bearing & 4.74 & 2.88 & 5.07 & Normal & $2205 / 1730$ \\
2 & Healthy bearing & 4.44 & 4.35 & 5.29 & Normal & $1470 / 175$ \\
3 & Healthy bearing & 2.30 & 5.86 & 5.10 & Normal & $735 / 1772$ \\
4 & Healthy bearing & 2.66 & 1.71 & 3.16 & Normal & $0 / 1797$ \\
5 & Inner race fault & 20.08 & 2.06 & 1.29 & I-Defect & $2205 / 1730$ \\
6 & Inner race fault & 19.93 & 3.32 & 2.75 & I-Defect & $1470 / 175$ \\
7 & Inner race fault & 17.58 & 1.61 & 1.21 & I-Defect & $735 / 1772$ \\
8 & Inner race fault & 16.87 & 1.33 & 2.27 & I-Defect & $0 / 1797$ \\
9 & Ball fault & 11.01 & 12.45 & 6.38 & B-Defect & $2205 / 1730$ \\
10 & Ball fault & 3.99 & 9.29 & 6.27 & B-Defect & $1470 / 175$ \\
11 & Ball fault & 8.47 & 9.05 & 10.76 & B-Defect & $735 / 1772$ \\
12 & Ball fault & 4.50 & 7.30 & 6.29 & B-Defect & $0 / 1797$ \\
13 & Outer race fault & 1.97 & 1.68 & 16.08 & O-Defect & $735 / 1772$ \\
14 & Outer race fault & 6.17 & 1.54 & 23.82 & O-Defect & $2205 / 1730$ \\
15 & Outer race fault & 0.77 & 0.75 & 13.74 & O-Defect & $0 / 1772$ \\
16 & Outer race fault & 5.25 & 1.78 & 22.81 & O-Defect & $1470 / 175$ \\
17 & Outer race fault & 1.80 & 1.30 & 16.10 & O-Defect & $735 / 1772$ \\
\hline
\end{tabular}

Table 4. Range of statistical indexes of inner defects for each defect level.

\begin{tabular}{ccccccc}
\hline $\begin{array}{c}\text { Fault } \\
\text { location }\end{array}$ & $\begin{array}{c}\text { Statistical } \\
\text { indexes }\end{array}$ & Healthy & Slight & Moderate & Severe & $\begin{array}{c}\text { Very } \\
\text { severe }\end{array}$ \\
\hline \multirow{5}{*}{ Inner race } & Maximum value & $<0.40$ & $0.40-1.80$ & $1.80-2.20$ & $2.20-3.80$ & $\geq 3.80$ \\
& PTP value & $<0.80$ & $0.80-3.30$ & $3.30-4.20$ & $4.20-7.20$ & $\geq 7.20$ \\
& Standard deviation & $<0.08$ & $0.20-0.35$ & $0.08-0.20$ & $0.35-0.6$ & $\geq 0.6$ \\
& Median absolute deviation & $<0.06$ & $0.15-0.30$ & $0.06-0.15$ & $0.30-0.50$ & $\geq 0.50$ \\
& Mean absolute deviation & $<0.06$ & $0.15-0.30$ & $0.06-0.15$ & $0.30-0.50$ & $\geq 0.50$ \\
& Peak/RMS & $<0.08$ & $0.20-0.35$ & $0.08-0.20$ & $0.35-0.60$ & $\geq 0.60$ \\
& Maximum value & $<0.36$ & $0.36-0.75$ & $0.75-2.30$ & $2.30-3.50$ & $\geq 3.50$ \\
& PTP value & $<0.70$ & $0.70-1.50$ & $1.50-5.00$ & $5.00-7.00$ & $\geq 7.00$ \\
& Standard deviation & $<0.08$ & $0.08-0.15$ & $0.15-0.18$ & $0.18-0.40$ & $\geq 0.40$ \\
& Median absolute deviation & $<0.06$ & $0.11-0.12$ & $0.06-0.11$ & $0.12-0.30$ & $\geq 0.30$ \\
& Mean absolute deviation & $<0.06$ & $0.11-0.12$ & $0.06-0.11$ & $0.12-0.30$ & $\geq 0.30$ \\
& Peak/RMS & $<0.08$ & $0.08-0.15$ & $0.15-0.18$ & $0.18-0.50$ & $\geq 0.50$ \\
& Maximum value & $<0.35$ & $1.00-3.70$ & $0.35-1.00$ & $3.70-6.70$ & $\geq 6.70$ \\
& PTP value & $<0.70$ & $1.40-7.50$ & $0.70-1.40$ & $7.5-13.5$ & $\geq 13.5$ \\
& Kurtosis & $<3.00$ & $3.80-8.00$ & $3.00-3.80$ & $8.00-24.00$ & $\geq 24.00$ \\
& Crest factor & $<5.20$ & $5.20-5.60$ & $5.60-7.10$ & $7.10-12.00$ & $\geq 12.00$ \\
& Impulse factor & $<7.00$ & $8.40-9.20$ & $7.00-8.40$ & $9.20-25.00$ & $\geq 25.00$ \\
\hline
\end{tabular}

Table 5. Statistical indexes of vibration signals of the severe defect in the inner ring.

\begin{tabular}{ccccccc}
\hline $\begin{array}{c}\text { Statistical } \\
\text { indexes }\end{array}$ & $\begin{array}{c}\text { Maximum } \\
\text { value }\end{array}$ & $\begin{array}{c}\text { PTP } \\
\text { value }\end{array}$ & $\begin{array}{c}\text { Standard } \\
\text { deviation }\end{array}$ & $\begin{array}{c}\text { Median } \\
\text { absolute } \\
\text { deviation }\end{array}$ & $\begin{array}{c}\text { Mean } \\
\text { absolute } \\
\text { deviation }\end{array}$ & Peak/RMS \\
\hline$s_{i}$ & 3.68 & 6.97 & 0.44 & 0.30 & 0.30 & 0.44 \\
\hline
\end{tabular}


Table 6. Statistical indexes of vibration signals of the very severe defect in the ball.

\begin{tabular}{ccccccc}
\hline $\begin{array}{c}\text { Statistical } \\
\text { indexes }\end{array}$ & $\begin{array}{c}\text { Maximum } \\
\text { value }\end{array}$ & $\begin{array}{c}\text { PTP } \\
\text { value }\end{array}$ & $\begin{array}{c}\text { Standard } \\
\text { deviation }\end{array}$ & $\begin{array}{c}\text { Median } \\
\text { absolute } \\
\text { deviation }\end{array}$ & $\begin{array}{c}\text { Mean } \\
\text { absolute } \\
\text { deviation }\end{array}$ & Peak/RMS \\
\hline$s_{b}$ & 11.67 & 21.77 & 2.03 & 1.53 & 1.53 & 2.03 \\
\hline
\end{tabular}

Table 7. Statistical indexes of vibration signal of the slight defect in the outer ring.

\begin{tabular}{cccccc}
\hline $\begin{array}{c}\text { Statistical } \\
\text { indexes }\end{array}$ & $\begin{array}{c}\text { Maximum } \\
\text { value }\end{array}$ & $\begin{array}{c}\text { PTP } \\
\text { value }\end{array}$ & Kurtosis & $\begin{array}{c}\text { Crest } \\
\text { factor }\end{array}$ & $\begin{array}{c}\text { Impulse } \\
\text { factor }\end{array}$ \\
\hline$s_{O}$ & 3.11 & 6.12 & 7.85 & 5.43 & 8.86 \\
\hline
\end{tabular}

the proposed detection system. SI indicates the degree of inner ring defect, SB indicates the degree of ball defect, and SO indicates the degree of outer ring defect. The thresholds for different systems are human-designed. The accuracy of the detection system is determined by the designed calculated method. Thus, the accuracy of detection does not depend on the human factor.

\subsection{Fault Size Range Detection}

According to the 17 studied fault cases from, ${ }^{31}$ the thresholds of the effective statistical indexes used in the proposed detection system are listed in Table 4 . The details of the calculation method are given in. ${ }^{30}$

Three fault cases, including inner race, ball, and outer race faults in Fig. 11 are used to validate the fault size range detections module. The detection results are listed in Tables 5 to 7, respectively. As shown in Table 5, the 6 statistical indexes are larger than the above defined threshold for the severe inner race faults; it can be defined as the bearing with the severe inner race fault. As shown in Table 6, the 6 statistical indexes are larger than the above defined threshold for the severe ball fault; it can be defined as the bearing with the severe ball fault. As shown in Table 7, the 5 statistical indexes are larger than the above defined threshold for the slight outer race fault; it can be defined as the bearing with the slight outer race fault. The above results can provide validation for the proposed detection system.

\section{CONCLUSIONS}

In this paper, an intelligent detection system for a ball bearing with local faults is developed based on NI LabVIEW software. This system includes the bearing fault parameters for determination, signal acquisition, envelope analysis, timedomain parameter analysis and bearing fault status modules. A case study for the calculation and analysis for the frequency and time-domain accelerations is presented to predict the location and size of the local fault in the ball bearing. The test data from the Case Western Reserve University Bearing Data Center is used to verify the developed intelligent detection system for local faults in a ball bearing. The results show that the proposed detection system can be used to detect the local fault in ball bearings. This study can provide some guidance for developing an efficient, fast and accurate local fault detection system for the quality of ball bearings.

\section{ACKNOWLEDGEMENTS}

The authors are grateful for the National Natural Science Foundation of China (No. 51605051), Chongqing Research Program of Basic Research and Frontier Technology (No. cstc2017jcyjAX0202).

\section{REFERENCES}

1 J. Liu, Y. Shao. Overview of dynamic modelling and analysis of rolling element bearings with localized and distributed faults, Nonlinear Dynamics. 2018, 93(4): 1765-1798. https://dx.doi.org/10.1007/s11071-018-4314-y

2 L. Y. Song, H. Q. Wang, P. Chen. Vibration based intelligent fault diagnosis for roller bearings in lowspeed rotating machinery, IEEE Transactions on Instrumentation and Measurement, 2018, 67(8): 1887-1899. https://dx.doi.org/10.1109/TIM.2018.2806984

3 L. L. Cui, Y. Zhang, F. B. Zhang, J. Y. Zhang, S. C. Lee. Vibration response mechanism of faulty outer race rolling element bearings for quantitative analysis, Journal of Sound and Vibration, 2016, 364: 67-76. https://dx.doi.org/10.1016/j.jsv.2015.10.015

${ }^{4}$ L. Guo, N. P. LI, F. Jia, Y. G. Lei, J. Lin. A recurrent neural network based health indicator for remaining useful life prediction of bearings, Neurocomputing, 2017, 240: 98-109. https://dx.doi.org/10.1016/j.neucom.2017.02.045

5 J. Liu, Y. Shao. Dynamic modeling for rigid rotor bearing systems with a localized defect considering additional deformations at the sharp edges, Journal of Sound and Vibration, 2017, 398(23):84-102. https://dx.doi.org/10.1016/j.jsv.2017.03.007

6 Y. Wang, T. W. Peter, B. P. Tang, Y. Qin, D. Lei, T. Huang. Kurtogram manifold learning and its application to rolling bearing weak signal detection, Measurement, 2018, 127: 533-545. https://dx.doi.org/10.1016/j.measurement.2018.06.026

7 S. Dong, X. Xu, J. Luo. Mechanical fault diagnosis method based on LMD Shannon entropy and improved fuzzy Cmeans clustering, International Journal of Acoustics and Vibration, 2017, 22(2): 211-217.

8 A. Moosavian, S. M. Jafari, M. Khazaee, H. Ahmadi. A comparison between ann, svm and least squares svm: application in multi-fault diagnosis of rolling element bearing, International Journal of Acoustics and Vibration, 2018, 23(4): 432-440. 
${ }^{9}$ L. Y. Song, H. Q. Wang, P. Chen. Step-by-step Fuzzy Diagnosis Method for Equipment Based on Symptom Extraction and Trivalent Logic Fuzzy Diagnosis Theory, IEEE Transactions on Fuzzy Systems, 2018, 3467 - 3478. https://dx.doi.org/10.1109/TFUZZ.2018.2833820

${ }^{10}$ H. Q. Wang, S. Li, L.Y. Song, L. L. Cui. A novel convolutional neural network based fault recognition method via image fusion of multi-vibrationsignals, Computers in Industry, 2019, 105: 182-190. https://dx.doi.org/10.1016/j.compind.2018.12.013

${ }^{11}$ L. L. Cui, J. F. Huang, F. B. Zhang, F. L. Chu. HVSRMS localization formula and localization law: Localization diagnosis of a ball bearing outer ring fault, Mechanical Systems and Signal Processing, 2019, 120(1): 608-629. https://dx.doi.org/10.1016/j.ymssp.2018.09.043

12 L. L. Cui, X. Wang, Y. G. Xu, H. Jiang, J. P. Zhou. A novel Switching Unscented Kalman Filter method for remaining useful life prediction of rolling bearing, Measurement, 2019, 135: 678-684. https://dx.doi.org/10.1016/j.measurement.2018.12.028

${ }^{13}$ L. L. Cui, X. Wang, H. Q. Wang, N. Wu. Improved Fault Size Estimation Method for Rolling Element Bearings Based on Concatenation Dictionary, IEEE Access, 2019, https://dx.doi.org/10.1109/ACCESS.2019.2899036

${ }^{14}$ M. Zhao, J. Lin, Y. Miao, X. Xu. Detection and recovery of fault impulses via improved harmonic product spectrum and its application in defect size estimation of train bearings, Measurement, 2016, 91: 421-439. https://dx.doi.org/10.1016/j.measurement.2016.05.068

15 M. Zhao, X. Jia. A novel strategy for signal denoising using reweighted SVD and its applications to weak fault feature enhancement of rotating machinery, Mechanical Systems and Signal Processing, 2017, 94: 129-147. https://dx.doi.org/10.1016/j.ymssp.2017.02.036

16 J. Liu, Y. Shao, T. C. Lim. Vibration analysis of ball bearings with a localized defect applying piecewise response function, Mechanism and Machine Theory, 2012, 56: 156-169. https://dx.doi.org/10.1016/j.mechmachtheory.2012.05.008

17 J. Liu, C. Tang, Y. Shao. An innovative dynamic model for vibration analysis of a flexible roller bearing, Mechanism and Machine Theory, 2019, 135: 27-39. https://dx.doi.org/10.1016/j.mechmachtheory.2019.01.027

18 J. Liu, Y. Shao. An improved analytical model for a lubricated roller bearing including a localized defect with different edge shapes, Journal of Vibration and Control, 2018, 24(17): 3894-3907. https://dx.doi.org/10.1177/1077546317716315

19 C. Mishra, A. K. Samantaray, G. Chakraborty. Rolling element bearing fault diagnosis under slow speed operation using wavelet de-noising, Measurement, 2017, 103:77-86. https://dx.doi.org/10.1016/j.measurement.2017.02.033
${ }^{20}$ C. Mishra, A. K. Samantaray, G. Chakraborty. Rolling element bearing defect diagnosis under variable speed operation through angle synchronous averaging of wavelet de-noised estimate, Mechanical Systems \& Signal Processing, 2016, 72-73:206-222. https://dx.doi.org/10.1016/j.ymssp.2015.10.019

21 J. B. Ali, N. Fnaiech, L. Saidi, et al. Application of empirical mode decomposition and artificial neural network for automatic bearing fault diagnosis based on vibration signals, Applied Acoustics, 2015, 89(3):16-27. https://dx.doi.org/10.1016/j.apacoust.2014.08.016

22 D. T. Hoang, H. J. Kang. Rolling Element Bearing Fault Diagnosis using Convolutional Neural Network and Vibration Image, Cognitive Systems Research, 2018. https://dx.doi.org/10.1016/j.cogsys.2018.03.002

23 B. An. Research and development of bearing vibration measuring instrument, Master thesis, Dalian University of Technology, Dalian, 2013.

${ }^{24} \mathrm{~T}$. W. Xie. Research on ball bearing vibration experiment and its analysis, Master thesis, Dalian University of Technology, Dalian, 2013.

${ }^{25}$ Z. Z. He, Y. X. Chen, M. H. Shao, X. D. Xu. On-line detection system for defect of rolling element bearings based on LabView, Instrument Technique and Sensor, 2017, 7: $72-75$.

26 W. A. Smith, R. B. Randall. Rolling element bearing diagnostics using the Case Western Reserve University data: A benchmark study, Mechanical Systems and Signal Processing, 2015, 64-65. https://dx.doi.org/10.1016/j.ymssp.2015.04.021

27 Z. Z. He, Y. X. Chen, M. H. Shao. On-line detection method for scoring defects on rolling surface of ball bearings, Bearing, 2018, 3: 55-60.

${ }^{28}$ X. H. Liang, Z. L. Liu, J. Pan, M. J. Zuo. Spur gear tooth pitting propagation assessment using model-based analysis, Chinese Journal of Mechanical Engineering, 2017, 30(6): 1369-1382. https://dx.doi.org/10.1007/s10033-017-0196$\mathrm{z}$

29 Z. L. Liu, M. J. Zuo, H. B. Xu. Fault diagnosis for planetary gearboxes using multi-criterion fusion feature selection framework, Journal of Mechanical Engineering Science, 2013, 227(9): 2064-2076.

30 J. Liu, Z. Xu, L. Zhou, W. Yu, Y. Shao. A statistical feature investigation of the spalling propagation assessment for a ball bearing, Mechanism and Machine Theory, 2019, 131: 336-350. https://dx.doi.org/10.1016/j.mechmachtheory.2018.10.007

31 K. A. Loparo. Bearings Vibration Data Set, [EB/OL], Case Western Reserve University, 2008. 